\title{
Risk factors of atrial fibrillation occurring after radical surgery of esophageal carcinoma
}

\author{
Jun Tang ${ }^{1}$, Jian-zhu Zhao ${ }^{2}$, Kai-ming Ren ${ }^{1}$, Fu-shuang Zheng ${ }^{1}$, Xi-wen Wang ${ }^{1}$, Hai-jun Liu', Jun-gang Zhao' and
} Ji-bin Lu' ${ }^{1 *}$

\begin{abstract}
Background: Atrial fibrillation (AF) is a common complication after radical surgery of esophageal cancer. The aim of this study was to explore AF risk factors after radical surgery of esophageal carcinoma.

Method: The data of 335 patients with esophageal cancer who were admitted in our hospital from January 2014 to August 2016 for the first time were retrospectively analyzed. We retrieved the papers in some data banks using the search terms including English and Chinese search terms, and obtained 13 factors which were mentioned in more than 6 papers. The 13 factors including age, gender, history of smoking, history of hypertension, history of peripheral vascular disease, history of cardiac stents or angina pectoris, preoperative pulmonary infection, preoperative brain natriuretic peptide (BNP) level, preoperative left ventricular diastolic dysfunction, operative method, lesion location, intraoperative blood transfusion, adhesion between lymph nodes and pericardium, underwent univariate and multivariate analyses.

Results: Of the 335 patients with esophageal cancer, 48 had AF within one week after operation. Univariate analysis indicated that the age (OR: 4.89; Cl: 2.53-9.47, P: 0.000), gender (OR: 2.26; Cl: 1.17-4.37, P: 0.013), history of peripheral vascular disease (OR: 2.29; Cl: 1.06-4.92, P: 0.030), history of cardiac stents or angina pectoris (OR: 27.30; Cl: 12.44-59.91, $P: 0.000)$, preoperative BNP level (OR: 27.13; Cl: 10.97-67.06, $P: 0.000)$, preoperative left ventricular diastolic dysfunction (OR: 2.22; Cl: 1.19-4.14, P: 0.012), operative method (OR: 2.09; Cl: 1.002-4.380, P: 0.046), intraoperative blood transfusion (OR: 20.24; Cl: 8.39-48.82, P: 0.000), and adhesion between lymph nodes and pericardium were risk factors (OR: 2.05; $C l: 1.08-3.87, P: 0.024)$. Furthermore, multivariate analysis displayed that advanced age (OR: 5.044; Cl: 1.748-14.554, P: 0. 003), male (OR: 6.161; Cl: 2.143-17.715, P: 0.001), history of cardiac stents or angina pectoris (OR: 48.813; Cl: 13.674-174. 246, P: 0.000), preoperative BNP > 100 (OR: 41.515; Cl: 9.380-183.732, P: 0.000), open surgery (OR: 3.357; Cl: 1.026-10.983, $P: 0.045$ ), intraoperative blood transfusion (OR: 58.404; Cl: 10.777-316.509, $P: 0.000$ ), and adhesion between lymph nodes and pericardium (OR: 3.954; Cl: 1.364-11.459, P: 0.011) were risk factors which could increase the incidence of postoperative AF.
\end{abstract}

Conclusion: We should pay attention to the above risk factors in order to reduce the incidence of postoperative AF.

Keywords: Radical surgery of esophageal cancer, Atrial fibrillation, Risk factors

\footnotetext{
* Correspondence: yuner3021@sina.com

${ }^{1}$ Department of Thoracic Surgery, Shengjing Hospital of China Medical

University, Shenyang 110004, China

Full list of author information is available at the end of the article
}

(c) The Author(s). 2019 Open Access This article is distributed under the terms of the Creative Commons Attribution 4.0 International License (http://creativecommons.org/licenses/by/4.0/), which permits unrestricted use, distribution, and reproduction in any medium, provided you give appropriate credit to the original author(s) and the source, provide a link to the Creative Commons license, and indicate if changes were made. The Creative Commons Public Domain Dedication waiver (http://creativecommons.org/publicdomain/zero/1.0/) applies to the data made available in this article, unless otherwise stated. 


\section{Introduction}

Postoperative atrial fibrillation (AF) has been one of the most common complications after general thoracic surgery. As early as 1974, M. Haimov, and S. Glabman reported a high incidence of AF after general thoracic surgery [1]. Most studies have shown that the incidence of postoperative AF is between 4 and $37 \%$ [2]. It usually occurs in an early stage (1-3 days) after radical surgery of esophageal cancer [3]. Postoperative AF will further increase the risk of stroke or thrombosis, mortality, hospital day and health care cost [4]. Paying attention to these high risk factors can decrease both the incidence of postoperative AF and the cost of hospitalization. In this study, many potential risk factors related to AF occurring after radical surgery of esophageal cancer were analyzed to find out the risk factors of postoperative AF, providing a basis for prevention of postoperative AF in clinical practice.

\section{Materials and methods Subjects}

A total of 375 consecutive patients who underwent radical surgery of esophageal cancer in our hospital between January 2014 and August 2016 for the first time were collected. The inclusion criteria were (1) age $>18$ years and (2) the patients receiving radical surgery of esophageal cancer. The exclusion criteria were (1) no rigorous preoperative evaluation (7 patients); (2) a history of cardiac arrhythmias before surgery (21 patients) and (3) no electrocardiogram monitoring within 1 week after operation (12 patients). The clinical data of 335 patients in line with the above inclusion and exclusion criteria were included in this retrospective study. Of the 335 patients, 262 were male and 73 female, with a mean of 63 years (range 40-88). In the 335 patients, 122 were over 70 years old; 262 were male, 202 had a history of smoking, 109 had a history of hypertension, 44 had a history of peripheral vascular disease, 42 had a history of cardiac stents or angina pectoris, 41 had preoperative pulmonary infection, 38 had preoperative $\mathrm{BNP} \geq 100,107$ had preoperative left ventricular diastolic dysfunction, 223 received open surgery, 182 had esophageal cancer in the upper middle segment, 28 received intraoperative blood transfusion and 166 had adhesion between lymph nodes and pericardium.

\section{Diagnostic criteria of postoperative $\mathrm{AF}$}

The postoperative AF was diagnosed according to the following 3 items: (1) The AF occurred within 1 week after radical surgery of esophageal cancer; (2) The AF was confirmed by electrocardiogram; and (3) The AF required drug intervention.

\section{Factors related to postoperative AF}

We retrieved the papers in the data banks including PubMed (January, 1992 to August, 2016), OVID Evidence-Based Medicine Database (January, 1994 to August, 2016), full-text database of Chinese journals (January, 1994 to August, 2016), VIP database (January, 1994 to August, 2016) and Wanfang database (January 1994 to August, 2016) using the search terms including English search terms such as esophageal cancer, atrial fibrillation, radical surgery and risk factors, as well as Chinese search terms such as食管癌, 房颤, 根治手术 and风险因素. We obtained 78 papers about AF risk factors after radical surgery of esophageal cancer. There were 13 factors which were mentioned in more than 6 papers, so the 13 factors were used as suspicious risk factors of postoperative AF. The 13 factors included age, gender, history of smoking, history of hypertension, history of peripheral vascular disease, history of cardiac stents or angina pectoris, preoperative pulmonary infection, preoperative brain natriuretic peptide (BNP) level, preoperative left ventricular diastolic dysfunction, operative method, lesion location, intraoperative blood transfusion and adhesion between lymph nodes and pericardium.

\section{Treatment of postoperative AF}

The patients who had postoperative AF were treated. In details, for the patients who had AF within $24 \mathrm{~h}$ after radical surgery of esophageal cancer, cordarone was directly used for cardioversion of AF to sinus rhythm; for the patients who had AF $24 \mathrm{~h}$ after radical surgery of esophageal cancer, cordarone was used for cardioversion of AF to sinus rhythm after atrial thrombosis was excluded or patients received 3-week anticoagulant; and for the patients who had recurrent attacks of AF for 3 times or over; radiofrequency ablation was used for cardioversion of AF to sinus rhythm.

\section{Statistical analysis}

SPSS 18.0 statistical software was used for statistical analysis. All the 13 suspicious risk factors were analyzed by univariate analysis. The factors which showed statistically significant differences in the univariate analysis were further analyzed by multivariate logistic regression analysis. The difference was statistically significant at $P<0.05$.

\section{Results}

\section{Clinical outcomes}

AF occurred within $24 \mathrm{~h}$ after radical surgery of esophageal cancer in 15 cases, within 2 to 3 days after radical surgery of esophageal cancer in 19 cases, within 4 to 5 days after radical surgery of esophageal cancer in 8 cases and 6 to 7 days after radical surgery of esophageal cancer in 6 cases. 
Of the 48 patients with postoperative AF, successful cardioversion of AF to sinus rhythm was performed by cordarone on 47 patients and by radiofrequency ablation on one patient.

\section{Univariate analysis}

The univariate analysis indicated that there were significant differences in the proportion of postoperative AF between over 70-year-old patients (27\%) and under 70-year-old patients (7\%) (OR: 4.89; CI: 2.53-9.47, P: $0.000)$, male patients $(23.3 \%)$ and female patients $(11.0 \%)$ (OR: 2.26; CI: 1.17-4.37, P: 0.013), the patients with a history of peripheral vascular disease $(25.0 \%)$ and the patients without a history of peripheral vascular disease (12.7\%) (OR: 2.29; CI: 1.06-4.92, P: 0.030), the patients with a history of cardiac stents or angina pectoris (66.7\%) and the patients without a history of cardiac stents or angina pectoris $(6.8 \%)$ (OR: 27.30; CI: 12.4459.91, $P: 0.000)$, the patients with preoperative BNP $\geq 100$ (72.4\%) and the patients with preoperative BNP < 100 (8.8\%) (OR: 27.13; CI: 10.97-67.06, P: 0.000), the patients with preoperative left ventricular diastolic dysfunction (21.5\%) and the patients without preoperative left ventricular diastolic dysfunction (11.0\%) (OR: 2.22; $C I: 1.19-4.14, P: 0.012)$, the patients receiving open surgery $(17.0 \%)$ and the patients receiving thoracoscopic surgery (8.9\%) (OR: 2.09; CI: 1.002-4.380, P: 0.046), the patients receiving intraoperative blood transfusion $(67.9 \%)$ and the patients not requiring intraoperative blood transfusion (9.4\%) (OR: 20.24; CI: 8.39-48.82, P: 0.000 ), as well as the patients with adhesion between lymph nodes and pericardium (18.7\%) and the patients without adhesion between lymph nodes and pericardium (10.1\%) (OR: 2.05; CI: 1.08-3.87, P: 0.024).

By contrast, the univariate analysis also displayed that there were no significant differences in the proportion of postoperative AF between the patients with a history of smoking (14.4\%) and the patients without a history of smoking (14.3\%) (OR: 1.006; CI: 0.538-1.880, P: 0.986), the patients with a history of hypertension (18.3\%) and the patients without a history of hypertension $(12.4 \%)$ (OR: 1.59; CI: $0.85-2.97, P: 0.145$ ), the patients with preoperative pulmonary infection $(14.6 \%)$ the patients without preoperative pulmonary infection (14.3\%) (OR: 1.03; CI: 0.41-2.59, $P: 0.952)$, as well as the patients with esophageal cancer occurring in the upper middle segment (13.7\%) and the patients with esophageal cancer occurring in the lower segment (15.0\%) (OR: 0.900; CI: 0.488-1.660, $P: 0.736$ ) (Table 1).

\section{Multivariate analysis}

After univariate analysis, the factors with values $P>0.05$ were excluded. The remaining factors with values $P<0.05$ were put into the logistic regression equation, proving that this regression equation was meaningful. Subsequently, multivariate analysis showed that age (OR: 5.044; $C I$ : 1.748-14.554, $P: 0.003)$, gender (OR: 6.161; CI: 2.143$17.715, P: 0.001)$, history of cardiac stents or angina pectoris (OR: 48.813; CI: 13.674-174.246, P: 0.000), preoperative BNP (OR: 41.515; CI: 9.380-183.732, P: 0.000), surgical methods (OR: 3.357; CI: 1.026-10.983, P: 0.045), intraoperative blood transfusion (OR: 58.404; CI: $10.777-$ 316.509, $P: 0.000$ ), as well as adhesion between lymph nodes and pericardium (OR: 3.954; CI: 1.364-11.459, P: 0.011 ) were the risk factors of postoperative AF (Table 2).

The distributions of these risk factors in the patients are shown in Table 3.

These factors increasing the risk of postoperative AF were as follows in the order from high to low: the intraoperative blood transfusion was 58.404 times, the history of cardiac stents or angina pectoris was 48.813 times, the preoperative $\mathrm{BNP} \geq 100$ was 41.515 times, the male was 6.161 times, the over 70-year-old age was 5.044 times, the adhesion between lymph nodes and pericardium was 3.954 times and the open surgery was 3.357 times (Table 2).

\section{Discussion}

Although clinicians have tried to reduce the occurrence of postoperative AF, it is still the most common complication after radical surgery of esophageal cancer. In this study, $14.3 \%$ of patients were complicated with postoperative AF. Nearly one-third (15 cases) of these patients developed atrial fibrillation within the first $24 \mathrm{~h}$ after surgery, $70.8 \%$ (34 cases) occurred within 3 days after surgery, and only $12.5 \%$ (6 cases) occurred 5 days after surgery. These data suggest that dynamic postoperative electrocardiogram is necessary, especially for the patients with risk factors of postoperative AF.

The results of this study showed that the risk of postoperative AF in over 70-year-old patients was 5.044 times the risk of postoperative AF in under 70-year-old patients. For aged people, their atrial and ventricular structures, systolic and diastolic functions, as well as electrocardio conduction have undergone structural changes. An epidemiological survey says that AF prevalence rates were more than $1 \%$, more than 5 and $10 \%$ in the people aged over 60 years, over 70 years and 80 years, respectively [5]. Surgery itself is an injury to the body and advanced age has always been a leading risk factor for perioperative cardiac complications. Amar et al. [6] observed the clinical data of 527 patients undergoing general thoracic surgery, and found that the incidence of postoperative AF was $4,8,14$ and $25 \%$ in the patients aged under $50,50-60,60-70$ and over 70 years, respectively. Their results are similar to that in this study and confirm that the incidence of postoperative AF increases with age. 
Table 1 Results of univariate analysis [n (\%)]

\begin{tabular}{|c|c|c|c|c|c|c|}
\hline Factors & No $A F(n=287)$ & $\operatorname{AF}(n=48)$ & $x^{2}$ & $P$ values & $O R$ & $95 \% \mathrm{Cl}$ \\
\hline \multicolumn{7}{|l|}{ Age } \\
\hline$<70$ & 198 (93\%) & $15(7 \%)$ & 25.29 & 0.000 & 4.89 & $(2.53,9.47)$ \\
\hline$\geq 70$ & $89(73 \%)$ & $33(27 \%)$ & & & & \\
\hline \multicolumn{7}{|l|}{ Gender } \\
\hline Male & $201(76.7 \%)$ & $61(23.3 \%)$ & 6.104 & 0.013 & 2.26 & $(1.17,4.37)$ \\
\hline Female & $65(89.0 \%)$ & $8(11.0 \%)$ & & & & \\
\hline \multicolumn{7}{|l|}{ History of smoking } \\
\hline No & $114(85.7 \%)$ & $19(14.3 \%)$ & 0.000 & 0.986 & 1.006 & $(0.538,1.880)$ \\
\hline Yes & $173(85.6 \%)$ & $29(14.4 \%)$ & & & & \\
\hline \multicolumn{7}{|l|}{ Hypertension } \\
\hline No & $198(87.6 \%)$ & $28(12.4 \%)$ & 2.127 & 0.145 & 1.59 & $(0.85,2.97)$ \\
\hline Yes & $89(81.7 \%)$ & $20(18.3 \%)$ & & & & \\
\hline \multicolumn{7}{|c|}{ History of peripheral vascular disease } \\
\hline No & $254(87.3 \%)$ & $37(12.7 \%)$ & 4.699 & 0.030 & 2.29 & $(1.06,4.92)$ \\
\hline Yes & $33(75 \%)$ & $11(25.0 \%)$ & & & & \\
\hline \multicolumn{7}{|c|}{ History of cardiac stents or angina pectoris } \\
\hline No & $273(93.2 \%)$ & $20(6.8 \%)$ & 107.16 & 0.000 & 27.30 & $(12.44,59.91)$ \\
\hline Yes & $14(33.3 \%)$ & $28(66.7 \%)$ & & & & \\
\hline \multicolumn{7}{|c|}{ Preoperative pulmonary infection } \\
\hline No & $252(85.7 \%)$ & $42(14.3 \%)$ & 0.004 & 0.952 & 1.03 & $(0.41,2.59)$ \\
\hline Yes & $35(85.4 \%)$ & $6(14.6 \%)$ & & & & \\
\hline \multicolumn{7}{|l|}{ Preoperative BNP } \\
\hline$<100$ & $279(91.2 \%)$ & $27(8.8 \%)$ & 87.261 & 0.000 & 27.13 & $(10.97,67.06)$ \\
\hline$\geq 100$ & $8(27.6 \%)$ & $21(72.4 \%)$ & & & & \\
\hline \multicolumn{7}{|c|}{ Preoperative left-ventricular diastolic dysfunction } \\
\hline No & $203(89.0 \%)$ & $25(11.0 \%)$ & 6.579 & 0.012 & 2.22 & $(1.19,4.14)$ \\
\hline Yes & $84(78.5 \%)$ & $23(21.5 \%)$ & & & & \\
\hline \multicolumn{7}{|l|}{ Operative methods } \\
\hline Combined & $102(91.1 \%)$ & $10(8.9 \%)$ & 3.996 & 0.046 & 2.09 & $(1.002,4.380)$ \\
\hline Open & $185(83.0 \%)$ & $38(17.0 \%)$ & & & & \\
\hline \multicolumn{7}{|l|}{ Lesion location } \\
\hline Lower & $130(85 \%)$ & $23(15.0 \%)$ & 0.114 & 0.736 & 0.900 & $(0.488,1.660)$ \\
\hline Middle or upper & $157(86.3 \%)$ & $25(13.7 \%)$ & & & & \\
\hline \multicolumn{7}{|l|}{ Blood transfusion } \\
\hline No & $278(90.6 \%)$ & $29(9.4 \%)$ & 71.31 & 0.000 & 20.24 & $(8.39,48.82)$ \\
\hline Yes & $9(32.1 \%)$ & 19 (67.9\%) & & & & \\
\hline \multicolumn{7}{|c|}{ Adhesion to pericardium } \\
\hline No & $152(89.9 \%)$ & $17(10.1 \%)$ & 5.064 & 0.024 & 2.05 & $(1.08,3.87)$ \\
\hline Yes & 135 (81.3\%) & 31 (18.7\%) & & & & \\
\hline
\end{tabular}

Notes: AF Atrial fibrillation, BNP Brain natriuretic peptide, $O R$ odds ratio, $C l$ confidence interval

Vaporciyan et al. [7] studied 2588 patients undergoing noncardiac thoracic surgery and believed that the risk factor of male sex may be related to the mechanism of immune response. Angele et al. [8] have proposed a hypothesis that the pro-inflammatory immune response caused by tissue trauma is more severe in male individuals than in female individuals, which is likely to lead to a higher incidence of 
Table 2 Result of multivariate logistic regression analysis

\begin{tabular}{lllllll}
\hline Factors & B & S.E & Wald & $P$ & $O R$ & $95 \% \mathrm{Cl}$ \\
\hline Age & 1.618 & 0.541 & 8.957 & 0.003 & 5.044 & $(1.748,14.554)$ \\
Gender & 1.818 & 0.539 & 11.384 & 0.001 & 6.161 & $(2.143,17.715)$ \\
History of peripheral vascular disease & 0.584 & 0.830 & 0.495 & 0.482 & 1.793 & $(0.352,9.124)$ \\
History of cardiac stents or angina pectoris & 3.888 & 0.649 & 35.864 & 0.000 & 48.813 & $(13.674,174.246)$ \\
Preoperative BNP & 3.726 & 0.759 & 24.106 & 0.000 & 41.515 & $(9.380,183.732)$ \\
Preoperative left-ventricular diastolic dysfunction & 0.926 & 0.604 & 2.349 & 0.125 & 2.524 & $(0.773,8.244)$ \\
Operative methods & 1.211 & 0.605 & 4.010 & 0.045 & 3.357 & $(1.026,10.983)$ \\
Blood transfusion & 4.067 & 0.862 & 22.252 & 0.000 & 58.404 & $(10.777,316.509)$ \\
Adhesion to pericardiaum & 1.375 & 0.543 & 6.409 & 0.011 & 3.954 & $(1.364,11.459)$ \\
\hline
\end{tabular}

Note: $B N P$ Brain natriuretic peptide, $O R$ odds ratio, $C l$ confidence interval

postoperative AF in men than in women after surgical trauma.

The results of this study showed that a history of cardiac stents or angina pectoris was a risk factor for the occurrence of AF after radical surgery of esophageal cancer, and the risk of postoperative $\mathrm{AF}$ in the patients with a history of heart stents or angina pectoris was 48.813 times the risk of postoperative $\mathrm{AF}$ in the patients without a history of heart stents or angina pectoris. There has also been a report of increased risk of postoperative cardiac complications in patients with underlying heart disease [9], which may be caused by the enlargement of atrial chamber, the pathological changes in the cardiac pacemaker conduction, and even the poor ability of cardiac function compensation and intolerance to anesthesia and surgery [10]. Therefore, there is no doubt that these patients are at high risk of perioperative arrhythmias, and a significant increase in the incidence of postoperative AF is understandable. These patients need to stop using anticoagulants more than 1 week before operation and preventive use of antiarrhythmic drugs is of certain significance [11].

Toufektzian et al. [12] reported that preoperative BNP was associated with AF after general thoracic surgery. The results of this study showed that the risk of postoperative AF in the patients with preoperative BNP $\geq 100$ was 41.515 times the risk of postoperative $\mathrm{AF}$ in the patients with preoperative $\mathrm{BNP}<100$. The patients with high BNP may not show the symptoms of heart failure before operation, but they may have got subclinical manifestations such as left atrial dilatation, cardiac dysfunction and so on [13]. N-terminal brain natriuretic peptide precursor (NT pro-BNP) is more susceptible to age, sex, and kidney function [14]. More and more data have proved that the increase of pre-operative BNP indicates the occurrence of postoperative cardiovascular adverse events, especially AF $[15,16]$. Therefore, BNP was a possible risk factor in this study. Generally speaking, BNP elevation indicates heart failure or atrial and ventricular wall dilatation, but it is also affected by age, atrial fibrosis, inflammation and unknown factors.

The results of this study indicated that the risk of postoperative AF in the patients receiving open surgery was 3.357 times the risk of postoperative $\mathrm{AF}$ in the patients receiving combined thoracoscopic surgery, which may be related to great trauma, heavy pain, slow recovery and other complications of open surgery. Compared with the patients receiving minimally invasive esophageal cancer surgery, the incidence of AF was increased in the patients receiving open esophageal cancer surgery [17]. The results of this study also showed that the risk of postoperative AF in the patients with intraoperative blood transfusion were 58.404 times the risk of postoperative $\mathrm{AF}$ in the patients without intraoperative blood transfusion and intraoperative blood transfusion was the biggest risk factor obtained in this study. Generally speaking, all operations requiring blood transfusion are complicated with bleeding, trauma, collateral damage and postoperative complications. Blood transfusion is easy to be complicated with AF after surgery due to insufficient fluid volume, electrolyte disturbance, immune changes and other factors [18]. Moskowitz et al. [19] suggests that debleaching red blood cells in mice may relieve severe inflammatory reactions and decrease the

Table 3 Distributions of risk factors of postoperative atrial fibrillation in these patients

\begin{tabular}{lcccccc}
\hline & Blood transfusion & $\begin{array}{l}\text { History of cardiac stents } \\
\text { or angina pectoris }\end{array}$ & $\begin{array}{c}\text { Preoperative } \\
\text { BNP } \geq 100\end{array}$ & Male & $\begin{array}{c}\text { Over 70-year-old age } \\
\text { Adhesion to } \\
\text { pericardium }\end{array}$ & $\begin{array}{c}\text { Open surgery } \\
\text { Patients }(n)\end{array}$ \\
\hline Note: $B N P$ Brain natriuretic peptide & 42 & 29 & 262 & 122 & 223 \\
\hline
\end{tabular}

Note: BNP Brain natriuretic peptide 
expression levels of various proinflammatory cytokines, which is the evidence that blood transfusions may lead to elevation of inflammation level.

It has been reported in many literatures that pericardial operation may increase the risk of AF [20-22]. In order to reveal the operative field, routine lymph node resection (subcarinal lymph nodes, adjacent esophageal lymph node and diaphragmatic lymph nodes) usually squeezes the pericardium, which is likely to lead to cardiac injury with the occurrence of postoperative AF. This study suggests that the risk of postoperative AF in the patients with adhesion between lymph nodes and pericardium was 3.954 times the risk of postoperative AF in the patients without adhesion, which seems to be consistent with the reported results above to some extent.

In this study, it is worth paying attention to that hypertension is not a risk factor of postoperative AF, which is different from other reports. Hypertension is a primary risk factor of AF [23], and approximately $53 \%$ of patients with AF have hypertension [24]. While, in this study, $32.5 \%$ of the patients had a history of hypertension before operation, and univariate analysis indicated that there was no statistically significant difference in the incidence rate of postoperative AF between the patients with and without a history of hypertension. This may be related to the insufficient sample size of this study.

The advantages of this study are as follows: Firstly, we observed only a complication (AF), and its risk factors were after receiving the same type of surgery (radical resection of esophageal cancer) in the same disease (esophageal cancer). Secondly, the dynamic review of electrocardiogram in this study strongly confirmed the diagnosis of AF. Finally, the risk factors in this study are all quantifiable factors, which are easy to attract the attention of surgeons and anesthesiologists before operation.

There are some limitations in this study as follows: Firstly, this retrospective study based on a single institution had its own limitations in controlling bias and confounding factors, as well as establishing causality and universality. Secondly, this study did not collect possible risk factors of postoperative AF such as electrolytes, hypoxia, anemia, hypothermia and other clinical data for statistical analysis, which may cause the interference of the results. Thirdly, because this study is a clinical study, it is not possible to deeply explore the molecular biological mechanism of these risk factors.

\section{Conclusions}

In summary, advanced age, male, a history of cardiac stents or angina pectoris, preoperative BNP $\geq 100$, open surgery, intraoperative blood transfusion and the adhesion between lymph nodes and pericardium are the risk factors associated with AF after radical surgery of esophageal carcinoma. Effective preoperative prevention for the above factors is likely to reduce the incidence of postoperative $\mathrm{AF}$ and greatly improve the prognosis of patients.

\section{Abbreviations \\ AF: Atrial fibrillation; BNP: Brain natriuretic peptide}

\section{Acknowledgments}

Not applicable.

\section{Funding}

None.

\section{Availability of data and materials}

All data generated or analyzed during this study are included in this published article.

\section{Authors' contributions}

JT was a major contributor in writing the manuscript. JZ, KR, FZ and XW analyzed and interpreted data. $\mathrm{HL}$ and $\mathrm{JZ}$ drafted tables. JL contributed to conception and design. All authors read and approved the final manuscript.

Ethics approval and consent to participate

All study methods were approved by the Ethics Committee of Shengjing Hospital of China Medical University.

Consent for publication

All patients gave written formal consent to participate.

\section{Competing interests}

The authors declare that they have no competing interests.

\section{Publisher's Note}

Springer Nature remains neutral with regard to jurisdictional claims in published maps and institutional affiliations.

\section{Author details}

${ }^{1}$ Department of Thoracic Surgery, Shengjing Hospital of China Medical University, Shenyang 110004, China. ${ }^{2}$ Department of Oncology, Shengjing Hospital of China Medical University, No 36, Sanhao Street, Herping District, Shenyang 110004, China.

Received: 14 November 2018 Accepted: 5 March 2019

Published online: 14 March 2019

\section{References}

1. Haimov M, Glabman S, et al. General surgery in patients on maintenance Hemodialys. Ann Surg. 1974;179:863-7.

2. Gomez-Caro A, Moradiellos MF, Ausin PF, Diaz-Hellin VF, Larru E, PerezAnton JA, et al. Risk factors for atrial fibrillation after thoracic surgery. Arch Bronconeumol. 2006:2:9-13.

3. Amar $\mathrm{D}$, Zhang $\mathrm{H}$. The incidence and outcome of ventricular arrhythmias after noncardiac thoracic surgery. Anesth Analg. 2002;95:537-43.

4. Konno O1, Tezuka T, Muto A, Hoshino Y. Postoperative arrhythmia after operation of esophageal cancer. Zasshi. 1993:41:45-51.

5. Xiujin Z, Xiaoying L. Analysis of factors influencing anticoagulation therapy in elderly patients with atrial fibrillation. Chin J Health Med. 2009;11:183-5.

6. Amar D, Zhang H, Leung DHY, Roistacher N, Kadish AH. Older age is the strongest predictor of postoperative atrial fibrillation. Anesthesiology. 2002; 96:352-6.

7. Vaporciyan AA, Correa AM, Rice DC, Roth JA, Smythe WR, Swisher SG, et al. Risk factors associated with atrial fibrillation after noncardiac thoracic surgery: analysis of 2588 patients. J Thorac Cardiovasc Surg. 2004;127:779-86.

8. Angele MK, Schwacha MG, Ayala A, Chaudry $\mathrm{H}$. Effect of gender and sex hormones on immune responses following shock. Shock. 2000;14:81-90.

9. Heng J, Yong W, Qin W, et al. Clinical analysis of risk factors associated with atrial fibrillation in hypertensive patients. Int J Cardiovasc Dis. 2013;40:57-9. 
10. Zhiru W, Min F, Qi L. Analysis on the related factors of arrhythmia after lung cancer resection [J/CD]. Chin J Clin Physicians (electronic edition). 2012;6:186-7.

11. Ojima T, Iwahashi M, Nakamori M, Nakamura M, Katsuda M, lida T, et al. Atrial fibrillation after esophageal cancer surgery: an analysis of 207 consecutive patients. Surg Today. 2014;44:839-47.

12. Toufektzian $L$, Zisis C, Balaka C, Roussakis A. Effectiveness of brain natriuretic peptide in predicting postoperative atrial fibrillation in patients undergoing non-cardiac thoracic surgery. Interact Cardiovasc Thorac Surg. 2015;20:654-7.

13. Raman T, Roistacher N, Liu J, Zhang H, Shi W, Thaler HT, et al. Preoperative left atrial dysfunction and risk of postoperative atrial fibrillation complicating thoracic surgery. J Thorac Cardiovasc Surg. 2012;143:482-7.

14. Sykes E, Karcher RE, Eisenstadt J, Tushman DA, Balasubramaniam M, Gusway J, Perason VJ. Analytical relationships among Bolsite, Bayer, and Roche methods for BNP and NT-proBNP. Am J Clin Pathol. 2005;123:584-90.

15. Xing SY, Wang HL, Dong PS, Lai LH, Zhu JH, Zhao JF, Shang XY. Clinical significance and levels of blood brain natriuretic peptides in patients with persistent atrial fibrillation before and after catheter ablation. Genet Mol Res. 2015;14:6953-9.

16. Nojiri T, Maeda H, Takeuchi Y, Funakoshi Y, Maekura R, Yamamoto K, Okumura M. Predictive value of B type natriuretic peptide for postoperative atrial fibrillation followinig pulmonary following pulmonary recection for lung cancer. Eur J Cardiothorac Surg. 2010;37:787-91.

17. Guangyi L, Lianfen X, Lin W. Comparison of curative effect between TV assisted thoracoscopic surgery (VATS) and thoracotomy for esophageal cancer. Mod Chin Doct. 2015;53:46-8.

18. Sun B, Wang J, Bo L, Zang Y, Gu H, Li J, Qian B. Effects of different anesthetic drugs and intraoperative blood transfusion on the immune function of patients with branchial carcinoma. Second Mil Med Univ. 2015 29:570-9.

19. Moskowitz DM, McCullough JN, Shander A, Klein JJ, Bodian CA, Goldweit RS, Ergin MA. The impact of blood conservation on outcomes in caediac surgery: is it safe and effective? Ann Thorac Surg. 2010;90:451-8.

20. Roselli EE, Murthy SC, Rice TW, Houghtaling PL, Pierce CD, Karchmer DP, Blackstone EH. Atrial fibrillation complicating lung cancer resection. J Thorac Cardiovasc Surg. 2005:130:438-44.

21. Gurgo AM, Ciccone AM, D'Andrilli A, Ibrahim M, Musumeci B, Quarta G, Saponaro A, Rendina EA, Volpe M. Plasma NT-proBNP levels and the risk of atrial fibrillation after major lung resection. Minerva Cardioangiol. 2008;56: $581-5$.

22. Zhiru W, Min C, Qi L. Analysis of factors related to arrhythmia after lung cancer lung cancer resection. Chin Clin J. 2012;(13):3745-6.

23. Kannel WB, Abbott RD, Savage DD, McNamara PM. Coronary heart disease and atrial fibrilation:the Framingham study. Am Heart J. 1983;106:389-96.

24. Wilhelmsen L, Rosengren A, Lappas $G$. Hospitalizations for atrial fibrillation in the general male population: morbidity and risk factom. J Intern Med. 2001; 250:382-9.

Ready to submit your research? Choose BMC and benefit from:

- fast, convenient online submission

- thorough peer review by experienced researchers in your field

- rapid publication on acceptance

- support for research data, including large and complex data types

- gold Open Access which fosters wider collaboration and increased citations

- maximum visibility for your research: over $100 \mathrm{M}$ website views per year

At $\mathrm{BMC}$, research is always in progress.

Learn more biomedcentral.com/submissions 